\title{
Physiotherapists Adapting to a Changing World
}

The world has forever been changed by the COVID-19 pandemic in ways that we may not fully appreciate until it is eventually under control worldwide. Healthcare professionals in different parts of the world have been battling for months to save lives from a highly contagious virus that has affected the way we live and think about the world. In these changing times, physiotherapists must learn to adapt and continue to provide the same quality of care we always have despite the challenges we are facing in this pandemic (Fauci et al., 2020). Physiotherapists are constantly updating their knowledge of treatment techniques, equipment, and effective patient care strategies using evidence-based guidelines as part of a lifelong commitment to continuing education within our field. We often play a critical role within interdisciplinary healthcare teams to ensure patients are receiving the best care possible so they may return to their highest level of functional potential. Whether we work in hospitals, aged care facilities, outpatient services or other settings, our overall goal is the same: to provide evidence-based treatment and individualised goals to improve health, function, and quality of life for our patients. A critical part of adaptation in this changing world is our contribution to interdisciplinary teamwork, which has always been vital to effectively and comprehensively plan patient care, but is now, perhaps, more important than ever.

The news regarding the COVID-19 pandemic and its effects around the world seems to change daily. For example, some countries, including New Zealand, have effectively decreased infection rates, while in other parts of the world, including the United States, the virus is claiming lives and infecting people in record numbers. While there is debate among public health officials and political leaders regarding the ways in which to address these growing numbers, our priority continues to be providing effective and quality care to our patients. In some cases, providing quality care is made more difficult by barriers we never could have imagined before the pandemic. In New Zealand, officials provided residents with clear guidelines and strategies for combatting the virus. However, in the United States, this has not been the case. One of the challenges healthcare workers have faced is a lack of adequate personal protective equipment (PPE). PPE is necessary to keep healthcare workers and patients safe, and without this, we are putting ourselves and our patients at risk. Other barriers and likely contributors to rising COVID-19 infection rates include a lack of understanding among the general public about ways they can help to prevent the spread of the infection, in particular cough and sneeze etiquette, wearing a mask, socially distancing at least $2 \mathrm{~m}$ apart, and hand washing. The high infection and hospitalisation rates have also affected hospital policies regarding visitors. Around the world there are many examples of family members not being allowed to visit sick relatives in order to limit their exposure to outside people, in some cases, contributing to feelings of isolation and fear.
Interdisciplinary teamwork is critically important in these times. We are challenged not only to care for patients infected with COVID-19, but also for other patients who are hospitalised or are within an inpatient setting and living in quarantine conditions due to the contagiousness of the virus. I have been a member of interdisciplinary healthcare teams for 25 years, firstly as a physiotherapist working in a variety of settings that have included rehabilitation centres, nursing facilities, and home settings. More recently, I returned to university for training to become a nurse (Bachelor of Science in Nursing), working in rehabilitation settings in both roles (physiotherapist and registered nurse) at different times/shifts. Throughout the years, the interdisciplinary teamwork I have been part of has contained different elements depending on the setting. For example, co-treatments with occupational therapists were common in nursing facilities, whereas in home settings, interdisciplinary communication might take the form of a written note or a phone call with a physical functioning update to a patient's nurse or other healthcare provider. The common element within any setting, however, was the importance of healthcare team communication to promote safety/continuity of care, for example between providers and between settings for discharge from acute care to home environments.

In adapting to the changing world, we as healthcare professionals can draw upon lessons learned from past medical crises. One example is the HIV/AIDs crisis when it began several decades ago. In the early days, little was known about how this virus was spread and who might be at risk of contracting it. Back then, healthcare professionals were on the front lines of caring for those patients, just like we are on the front lines caring for COVID-19 patients. Interdisciplinary team communication was critical to providing quality care for patients while also ensuring the safety of healthcare providers who may be exposed to bodily fluids, for example. Team members communicated in ways that were necessary and vital to the overall functioning of that healthcare environment. Another example is the response to the H1N1 pandemic a few years ago (Wong et al., 2012). Healthcare workers were challenged to contribute to the care and safety of these patients using the same effective communication strategies to keep both patients and healthcare workers safe. In today's crisis, we can apply these same lessons since we are facing the effects of a highly contagious virus. Among the ways we can adapt is by embracing different forms of communication, such as telehealth. This topic was discussed in the last editorial of this journal (Woodley, 2020) and was recently explored as a specific way of navigating the uncharted territory of the pandemic we are currently facing (Hollander \& Carr, 2020).

In this ever-changing world, interdisciplinary teamwork and communication has never been more important (Eklof \& Ahlborg, 2016). The consequences of a lack of good communication are compounded by this disease being highly 
infectious and poorly understood. We are seeking to fully understand the nature of transmission and why the disease affects different people in sometimes vastly different ways. Unfortunately, we are also facing the reality that there is not yet a vaccine or standardised treatment. We as physiotherapists must do our part as healthcare team members to adapt to our changing world.

Jennifer Rowland $P h D, P T, M S, M P H, B S N, R N$

Physiotherapist and nurse, Memorial Hermann Hospital and University of Houston-Clear Lake, Texas, United States Editorial Advisory Board member, New Zealand Journal of Physiotherapy

Email: jenrow19@gmail.com

https://doi.org/10.15619/NZJP/48.2.01

\section{REFERENCES}

Eklof, M., \& Ahlborg, G. (2016). Improving communication among healthcare workers: A controlled study. Journal of Workplace Learning, 28, 81-96. https://doi.org/10.1108/JWL-06-2015-0050

Fauci, A. S., Lane, C., \& Redfield, R. R. (2020). Covid-19 - Navigating the uncharted. New England Journal of Medicine, 382, 1268-1269. https:// doi.org/10.1056/NEJMe2002387

Hollander, J. E., \& Carr, B. G. (2020). Virtually perfect? Telemedicine for Covid-19. New England Journal of Medicine, 382, 1679-1681. https://doi. org/10.1056/NEJMp2003539

Wong, E. L., Wong, S. Y., Lee, N., Cheung, A., \& Griffith, S. (2012). Healthcare workers' duty concerns of working in the isolation ward during the novel H1N1 pandemic. Journal of Clinical Nursing, 21(9-10), 1466-1475. https://doi.org/10.1111/j.1365-2702.2011.03783.x

Woodley, S. (2020). Communication - An essential tool in extraordinary times. New Zealand Journal of Physiotherapy, 48(1), 5-6. https://doi. org/10.15619/NZJP/48.1.01 